\title{
Грузия сегодня: актуальные проблемы и новые вызовы в системе высшего образования
}

\author{
Л.А. Черешнева, У. Гаджиева \\ Липецкий государственный педагогический университет имени П.П. Семенова-Тян-Шанского, \\ Россия, 398020, Липецкая область, г. Липецк, ул. Ленина, 42 \\ E-mail: larisa-chereshneva@rambler.ru, ulyagadjieva2000@gmail.com
}

\begin{abstract}
Аннотация. В статье представлена история развития, становления и существования системы высшего образования Грузии советского и современного периода. Задача авторов - выявить основные проблемы образовательной системы, которая в ходе многочисленных изменений приобретает новые черты, и провести анализ возможных путей решения, представленных в виде национальных проектов. В работе также рассматриваются цели и характерные особенности крупнейших Европейских организаций по созданию единого образовательного пространства, обеспечения качества процесса обучения, полноправным участником которых является Грузия. Oсобое внимание уделяется Тбилисскому государственному университету имени И.А. Джавахишвили как единственному очагу высшего образования республики с 1918 г. и Академии наук, образованной в 1941 г. Исследуются условия выдачи потребительских кредитов для обучающихся, предоставляемых лидерами финансового сектора страны - «Банком Грузии» и «ТВС Банк». В заключении сделан вывод, что низкие зарплаты учителей и преподавателей, несовершенства «европеизированной» образовательной политики, сложности получения качественного образования представителями многочисленных коренных народов Грузии, слабая материально-техническая база - лишь малая часть «диагнозов», поставленных системе образования и науки республики сегодня.

Ключевые слова: система высшего образования, система образования и науки, Болонский процесс, Тбилисский государственный университет, Академия наук, Европейская ассоциация гарантии качества высшего образования (EQAR), ваучерная система, педагогические кадры, азербайджанцы, национальные меньшинства.
\end{abstract}

Благодарности: работа выполнена при грантовой поддержке Федерального агентства по делам молодежи, соглашение № 091-15-2019-104 от 04. 09. 2019.

Для цитирования: Черешнева Л.А., Гаджиева У. 2021. Грузия сегодня: актуальные проблемы и новые вызовы в системе высшего образования. Via in tempore. История. Политология, 48 (1): 97- 106, DOI: 10.52575/2687-0967-2021-48-1-97-106.

\section{Georgia today: current problems and new challenges in the system of Higher education}

\author{
Larisa A. Chereshneva, Ulkar Gadjieva \\ Lipetsk State Pedagogical named after P.P. Semenov-Tyan-Shansky University, \\ 42 Lenina St., Lipetsk, Lipetsk region, 398020, Russia \\ E-mail: larisa-chereshneva@rambler.ru, ulyagadjieva2000@gmail.com
}

\begin{abstract}
The article presents the history of the development, formation and existence of the higher education system of Georgia in the Soviet and modern periods. The task of the authors is to identify the main problems of the educational system, which, in the course of numerous improvements and changes, acquires new features, and to analyze the possible solutions presented in the form of national projects. The paper also discusses the goals and characteristics of the largest European organizations to create a
\end{abstract}


single educational space, to ensure this process with quality, of which Georgia is a full participant. Particular attention is paid to I.A. Javakhishvili Tbilisi State University, as the only center of higher education of the Republic since 1918 and the Academy of Sciences, founded in 1941. We study the conditions for issuing consumer loans for students provided by the leaders of the country's financial sector - the Bank of Georgia and TBC Bank. In conclusion, it was concluded that low salaries for teachers and lecturers, the imperfections of the «Europeanized» educational policy, and difficulties in obtaining the quality education by the representatives of numerous indigenous peoples of Georgia, a weak material and technical base is only that small part of the "diagnoses" made to the current education and science system of the Republic.

Keywords: higher education system, education and science system, Bologna process, Tbilisi State University, Academy of Sciences, European Higher Education Quality Assurance Association (EQAR), voucher system, teaching staff, Azerbaijanis, national minorities.

Acknowledgements: The work is supported by Federal Agency for Youth Affairs № 091-15-2019-104 of 04.09.2019.

For citation: Chereshneva L.A., Gadjieva U. 2021. Georgia today: current problems and new challenges in the system of higher education. Via in tempore. History and political science, 48 (1): 97-106 (in Russian). DOI: 10.52575/2687-0967-2021-48-1-97-106.

\section{Введение}

Быстрая динамика современных трендов глобализации и полицентризации, нестабильность мировой экономики, жесткая конкуренция на рынке труда обуславливают повышение внимания государств, а также частных работодателей к уровню и качеству профессиональных компетенций, осваиваемых специалистами в процессе обучения. Высшее образование «как самая крупная индустрия XX века» является фактором, определяющим благосостояние и само будущее молодежи во всем мире. Каждому развивающемуся государству сегодня свойственна своя образовательная политика, методы реформирования образования в условиях рыночной экономики. К системам, подвергающимся экспериментам и трансформациям во всех периодах истории, относится система высшего образования и науки Грузии.

Грузия - одна из перспективных и привлекательных стран Закавказья, известная местными рекреационными ресурсами, самобытной культурой, историческими достопримечательностями. Однако мало кто знает, что Грузия ежегодно принимает тысячи иностранных студентов, прибывающих из стран СНГ и Европы. Услуги высшего образования республики пользуются спросом благодаря достаточно высокому качеству, в целом стремящемуся соответствовать современным европейским стандартам. Грузинские университеты предлагают иностранным студентам целый спектр преимуществ образовательного процесса, среди которых относительно невысокая стоимость обучения (образование отличается доступностью даже для студентов с ограниченными финансовыми возможностями), выдача дипломов европейского образца, подготовка кадров, востребованных на современном рынке труда, реализация обучения на разных языках, включая подготовительные курсы по изучению государственного языка. Наряду с вышеперечисленными достоинствами системы высшего образования Республики Грузия существует целый перечень проблем, на решение которых направлена государственная политика.

\section{Экскурс в историю}

Перед тем как перейти к раскрытию ключевых проблем системы высшего образования и науки Грузии, путей решения выявленных задач, необходимо провести краткий обзор исторического развития республики в составе СССР и в ее независимом статусе отдельного государства. В этой связи особое место следует отвести Тбилисскому государ- 
ственному университету, функционирующему с 1918 г. В этом учебном заведении велась качественная подготовка многочисленных кадров разных специальностей для народного хозяйства и культурного развития республики.

Усилиями группы грузинских ученых и академиков во главе с И.А. Джавахишвили университет был значительно расширен. В частности, на базе соответствующих факультетов образовались Тбилисский политехнический институт, Грузинский сельскохозяйственный институт и Тбилисский медицинский институт [Вачнадзе, 1993, с. 155]. В результате комплексной работы Советской власти Тбилисский государственный университет стал одним из самых передовых в Советском Союзе.

Основатели университета избрали наиболее демократический путь комплектования факультетов студентами, предоставив возможность представителям всех слоев населения получать высшее образование [Васадзе, 1975, с. 22]. Однако академик И.А. Джавахишвили, в честь которого названо учебное заведение, утверждал, что жизнь и учеба в городе практически закрывали двери университета для детей из рабочих и крестьянских семей. Логичным объяснением тому выступает следующий факт: в первые годы нестабильного функционирования бюджет ТГУ формировался за счет платы за обучение (100 рублей за учебный год). Не исключено, что финансовые трудности возникали у иногородних студентов, прибывающих в Тбилиси из самых отдаленных регионов Грузии: Аджарии, Имеретии, Мцхеты, Квемо-Картли.

Примечательно, что Грузия, будучи в составе СССР, отличалась высокими темпами индустриализации. Наряду с другими закавказскими республиками она располагала развитой промышленностью. Не отставало от экономического развития и социальное. С 1935 г. было введено обязательное всеобщее обучение. Вскоре Грузия покрылась сетью образовательных центров по ликвидации безграмотности.

Уже с 60-х гг. прошлого столетия Грузинская ССР занимала лидирующее в Союзе место по количеству выпускников с дипломами о высшем образовании. Если в дореволюционной Грузии специалистов с высшим образованием можно было «сосчитать по пальцам», то в результате второй пятилетки (1933-1937 гг.) вузы выпустили 12436 специалистов, третьей пятилетки (1938-1941 гг.) - 10 991. В этот период времени профессия «педагог» пользовалась особой популярностью, востребованностью, отличалась высоким уровнем заработной платы.

Важным этапом развития грузинской национальной науки явилось основание в феврале 1941 г. Академии наук [Месхиа, 1968, с. 44]. Большой вклад в развитие науки внесли академики Н.А. Мусхелишвили, И.С. Бериташвили, И.Н. Векуа; членыкорреспонденты Академии наук СССР А.Г. Шанидзе, Г.С. Ахвледиани, Ш.Я. Амиранашвили и многие другие научные деятели. Исследования грузинских психологов, педагогов, математиков, физиков, естествоиспытателей и других представителей науки стали известны далеко за пределами Советского Союза.

В 1991 г. Грузия обрела независимость, ее первым президентом стал Звиад Гамсахурдия [Капальбо, 2019, с. 3]. Впервые за всю историю своего существования страна политически дистанцировалась от России на рубеже XX-XXI вв., стала демонстрировать суверенитет и стремление к региональному лидерству, антироссийские фобии, хотя при этом в 1994 г. присоединилась к СНГ [Рцхиладзе, 2018, с. 36]. При этом Грузия испытала «самый длительный и глубокий по сравнению почти со всеми другими странами СНГ (возможно, за исключением Армении) кризис экономики» [Гаджиев, 2001, с. 146]. Демографический кризис, коррупция госаппарата, бедность, национальные конфликты участь, которая постигла бывшую Грузинскую ССР в ее независимом развитии.

В условиях постсоветского пространства сохранить былой потенциал не удалось и системе высшего образования страны. В конце 1990-х гг. в политике Грузии стали заметны западные влияния, большинство политического класса определилось со своим выбором в пользу вступления в Европейский союз, что сказалось и на системе образования в целом 
[Кожокин, 2001, с. 7]. Итогом стало официальное присоединение Грузии к Болонскому процессу, и система образования и науки страны превратилась в поле для нововведений.

Остановимся на выяснении возможных потенциалов Болонской декларации. Так, «Болонский процесс надо рассматривать как совокупность кардинальных реформ высшего образования с целью придания последнему тех качеств, структур и параметров, которые соответствуют обществу знаний и востребованы этим обществом» [Гретченко, 2005, с. 38]. Следует добавить - западным обществом. Все страны-участницы Болонской декларации, в том числе и Грузия, преследуют одинаковые цели: повышение конкурентоспособности системы высшего образования; возможность личностной реализации и трудоустройства выпускников, обладающих профессиональными компетенциями, на современном европейском рынке труда. В свою очередь, Европейский Союз ежегодно выделяет более 100 миллионов евро на реализацию проектов Грузии, в том числе на поддержку модернизационной политики в сфере образования и науки в соответствии с Болонскими реформами [European Commission, 2018].

Рассмотрим ряд имеющихся особенностей Болонского процесса:

1. Целостность проводимых реформ.

2. Системная природа преобразований.

3. Противоречивый характер декларации (конкурентоспособность и в то же время сотрудничество, концентрация внимания на достоинствах и устранение имеющихся недостатков, социальная и экономическая функции высшего образования, высшее образование как «социальная составляющая» и как «рыночная услуга»).

4. Необходимость содействия проводимым преобразованиям.

Так, на правах подписанта Болонской декларации осенью 2019 г. Грузия стала официальным членом EURAXESS - структуры, созданной по инициативе Еврокомиссии. Целью ее является содействие мобильности исследователей в Европе и третьих странах и поддержка открытого рынка труда для исследователей. Бюджет EURAXESS составляет около 100 миллиардов евро. Это значит, что у грузинских ученых, преподавателей, учителей, студентов и школьников появилась возможность иметь открытый доступ к международным и внутренним научным грантам, поддерживать связь с иностранными университетами, научно-исследовательскими центрами и лабораториями по всему миру с учетом стратегических целей Еврокомиссии и ЕС.

\section{Масштабные реформы}

Разумеется, европейские стандарты и рекомендации коснулись не только вопросов продолжительности и форм обучения, но и содержания образовательного процесса. Например, в сферах социологии, философии, истории и экономики почти все учебные программы дополнены западными установками и идеями. Ещё одна «сторона медали» последовал упадок популярности и привлекательности точных наук и технических специальностей среди абитуриентов. Согласно показателям, самыми востребованными специальностями, исходя из потока абитуриентов на вступительных экзаменах, являются связанные с медициной, правом, экономикой и другими общественными дисциплинами, далеко позади «следуют» инженерия, энергетика, производственное обучение, сельское хозяйство [Gachechiladze, 2004, p. 79]. Возникает угроза дефицита кадров для промышленного и сельскохозяйственного сектора Грузии. Министерство образования и науки страны прилагает все усилия для улучшения преподавания точных и технических дисциплин в высших учебных заведениях. Политика реформирования образовательной системы проводится в два уровня:

1. На уровне среднего образования ведется финансирование участия школьников в международных олимпиадах по математике, физике и информатике, вследствие чего растет количество обучающихся, которые увлекаются математическими и техническими науками. 
2. На уровне высшего образования, в частности на базе ТГУ, благодаря сотрудничеству с Тбилисской компанией «Тэласи» по содействию эффективному развитию энергетического сектора экономики был сформирован научно-исследовательский центр, где для студентов проводились лекции, а для преподавателей и работников отраслевого сектора курсы повышения квалификации [REGNUM, 2006]. Согласно договору о партнерстве, лучшим студентам энергетического факультета университета были назначены именные стипендии, а также предоставлялась финансовая поддержка для студентов-отличников, которые имели желание продолжить обучение за рубежом. Студенты, полностью прошедшие квалификационные курсы, имели возможность трудоустроиться в АО «Тэласи».

Масштабная реформа образования включает 10 пакетов трансформаций. Планируется поэтапная реализация реформ в течение 4 лет. Эксперты утверждают, что основной целью реформ является превращение Грузии в потенциального лидера среди республик Закавказья.

Для понимания производимых в государстве изменений целесообразно представить обзор и анализ одного из пакетов реформ - по вхождению и полноправному членству Грузии в составе крупнейшей Европейской организации по обеспечению качества высшего образования. Европейская сеть обеспечения качества в высшем образовании (ENQA) начала свою деятельность еще в 2000 г. Е.Р. Борисова считает, что основной целью Европейской ассоциации гарантии качества высшего образования является «развитие сотрудничества, обмен успешным опытом и стимулирование развития европейских стран в области обеспечения качества образования» [Борисова, 2006, с. 182].

В планах Министерства образования и науки на 2019-2020 учебный год предполагалось вхождение Грузии в «Европейский реестр агентств обеспечения качества» (EQAR), отмена финансирования обучения на 21 факультете (гуманитарные, аграрные науки, инженерия и т. п.), переход на ваучерную систему, т. е. перераспределение ресурсов, направляемых на бюджетные места в вузах. Предполагается, что эти нововведения дадут привлекательные бонусы грузинской молодежи. Так, от членства Грузии в EQAR ожидается:

- помощь грузинским педагогам и студентам со стороны европейских партнеров;

- признание диплома и получаемой квалификации на международном уровне;

- установление партнерских отношений между грузинскими и западными вузами.

Перейдем к выяснению формата содействия банковского сектора Грузии студентам в процессе получения ими высшего образования. Еще в 2005 г. один из лидеров банковского сектора Грузии АО «Банк Грузии» («Georgia Bank») начал выдачу кредитов для студентов на льготных условиях [Вачнадзе, 2009, с. 176]. Абитуриентам, их родителям или иным представителям следует предъявить следующие документы: удостоверение личности, справку о доходах (не менее 150 лари в месяц), справку из вуза, подтверждающую обучение в нем студента. Также «Банк Грузии» ежегодно выпускает «студенческую карту», которая позволяет учащимся использовать программу начисления баллов PLUS, льготы на проезд в общественном транспорте, SMS-банк и Интернет-банк [Bank of Georgia, 2019].

Грузинский «ТВС Банк» начал выдачу студенческих кредитов с августа 2006 г. Кредит выдается каждому студенту, поступившему в вуз по итогам единых национальных экзаменов. Уровень кредитной ставки определяется наличием у будущего студента гранта.

На сегодняшний день система высшего образования Грузии практически полностью прошла все этапы европеизации. Ближайшие годы дадут возможность проанализировать себестоимость и степень эффективности этих нововведений и их влияние на ликвидацию экономических и социальных диспропорций независимой Грузии.

Вместе с тем сегодня противоречивое положение образовательной системы является отражением неоднозначной социальной жизни грузинского населения. Грузинское общество находится в состоянии «растерянности» и не знает, как правильно сделать выбор дальнейшего курса развития. 


\section{Проблемы получения образования представителями национальных меньшинств}

Далее целесообразно поднять еще одну актуальную проблему - получение высшего образования представителями национальных меньшинств, в частности - азербайджанцами, чья численность на территории Грузии составляет около 300 тысяч человек. Данный вопрос требует незамедлительного решения от Министерства науки, образования, культуры и спорта.

Привлеченный нами для исследования регион, известный до революции под названием Борчалы (Квемо-Картли) - один из наиболее многонациональных краев Грузии, где находится и историко-этнографическая зона азербайджанцев [Новрузов, 1991, с. 5]. Согласно данным последней переписи населения, в ноябре 2014 г. численность населения Квемо-Картли составила 423986 человек, около половины жителей этнически являются азербайджанцами, абсолютное большинство которых территориально относится к Марнеули, Дманисси, Гардабани [Грузия в цифрах, 2014]. Для сравнения: в 1989 г. в 52 населенных пунктах региона проживало 132074 чел., где число азербайджанцев достигло 61187 чел. [Ömərli, 2001, s. 126].

В настоящее время большинство выпускников средних школ Гардабанского, Марнеульского, Болнисского и Дманисского районов края не владеют даже самыми простыми грузинскими фразами и словосочетаниями. В данных регионах насчитывается около 78 школ, и в 58 заведениях занятия ведутся на азербайджанском или русском языках. Школьники Квемо-Картли составляют меньшую часть от общего числа грузинских школьников, но именно на их долю ежегодно приходятся 20-25 \% проваленных выпускных экзаменов.

Комплексно рассмотрим основные причины данной проблемы и соответствующие меры по их решению:

1. Количество занятий грузинского языка в неделю.

Грузинский язык - официальный язык республики, язык государственных органов, органов местного самоуправления, язык, на котором проходит обучение в школах, профессиональных училищах, университетах [Цибахашвили, 2001, с. 4]. В азербайджанских школах региона Квемо-Картли, в частности в образовательных учреждениях Гардабанского, Марнеульского и Болнисского муниципалитетов, у учеников начальных, средних и старших классов возникают трудности с освоением базовой программы таких учебных дисциплин, как математика, история, география, литература, языкознание. Разумеется, изза отсутствия подготовительных курсов по изучению грузинского языка получение дальнейшего образования для азербайджанской молодежи становится практически невозможным. Как итог, родители и попечители, обеспокоенные будущим своих детей, принимают решение покинуть Квемо-Картли.

2009 год стал решающим для будущих студентов из числа национальных меньшинств. Так, для оказания помощи абитуриентам-азербайджанцам в получении качественного высшего образования государство запустило образовательную программу «1+4». Главная идея проекта состоит в том, что выпускники школ год целенаправленно готовятся в университете, изучая грузинский язык, а после успешной сдачи экзамена автоматически зачисляются на заранее выбранный факультет или направление специализации, где срок обучения по программам бакалавриата составляет 4 года, магистратуры - 2.

С 2012 г. в Грузии осуществляется государственная программа «Грузинский язык для процветания». Добровольческие отряды численностью более 500 чел. отправляются в регион Квемо-Картли с целью преподавания грузинского языка ученикам начальной, средней и высшей школы.

Приведем пример реализации программы «1+4». На базе Тбилисского государственного университета имени Иванэ Джавахишвили, который является одним из ведущих научных центров, была начата учебно-методическая работа по преподаванию грузин- 
ского языка как родного и иностранного, для всех желающих ведутся языковые курсы. На протяжении всего курса обучения будущих студентов используются современные интерактивные методы качественного освоения языка. Образовательный центр предлагает курсы грузинского языка на всех уровнях в соответствии со стандартами, разработанными Европейским Советом: A1, A2, B1, B2, C1, C2. Обучение на каждом уровне охватывает один год, кроме уровня A1 - курс длится один семестр [TSU, 2019].

Однако первые итоги реализуемой государством программы оказались далеко не оптимистическими - лишь 792 студента воспользовались ею (данные на 2017-2018 учебный год). К тому же около 80 \% молодёжи бросают учёбу, ссылаясь на то, что занятия на грузинском языке вызывают у них сложности, в сжатые сроки освоить язык удаётся далеко не каждому.

Противоречивые настроения представителей национальных меньшинств можно объяснить и воздействием «Закона об общем образовании», подписанного бывшим президентом Грузии М. Саакашвили в апреле 2005 г. Анализируя этот законодательный акт, находим, что в пункте 1 статьи 4 говорится о том, что образовательный процесс в учреждениях среднего образования реализуется на официальном языке республики - грузинском. Исключение до событий 2008 г. составляла Абхазская Автономная Республика: там учениками самостоятельно мог быть выбран как основной, так и дополнительный языки для обучения - грузинский и абхазский. Обращаемся к пункту 3 статьи 4: «Граждане Грузии, для которых грузинский язык не является родным, имеют право получить полное общее образование на своем родном языке в соответствии с национальным учебным планом в порядке, установленном законодательством. В указанном общеобразовательном учреждении обязательно изучение государственного языка» [Закон об общем образовании. 2005. Статья 2].

2. Недостаток учебно-методических материалов для подготовки к занятиям.

Некачественная подготовка учебных и методических пособий по изучению грузинского языка, недостаточное количество рекомендуемого материала, непригодное физическое состояние учебников, справочников, методических разработок, в которых трудно прочитать необходимую информацию - еще один перечень проблем, в силу которых ученикам средних общеобразовательных азербайджанских школ республики тяжело освоить программу на грузинском языке.

3. Педагогический состав учебного заведения, не соответствующий запросам населения региона.

Прекращение обеспечения школ Квемо-Картли высокопрофессиональными педагогическим кадрами - наглядный пример равнодушия как грузинской, так и азербайджанской сторон к сложившемуся положению соотечественников, проживающих за территорией Азербайджана.

При этом нельзя не отметить, что одной из самых эффективных мер по ликвидации проблемы низкой квалификации учителей, предпринятых на государственном уровне в 2016 г., стала программа переподготовки педагогических кадров [Амирджанова, 2019]. Согласно программе, курсы переподготовки доступны для учителей 7-12 классов по таким дисциплинам, как география, биология, химия, математика, физика и английский язык. В целом около 25000 специалистов смогут пройти длительное обучение в рамках программы, которое помимо тренингов включает в себя образовательные семинары, лекции, разработку ресурсов и содействие внедрению новых практик в школьной среде [Ministry of Education, Science, Culture and Sport of Georgia, 2019].

Зарплата учителей и педагогов в Грузии сегодня зависит от результатов тестирования и получаемой категории:

1) 1 категория - учителя несертифицированные;

2) 2 категория - учителя сертифицированные;

3) 3 категория - доктора и кандидаты наук, преподаватели с учеными званиями, практикующие в школе. 
Один из программных «пакетов» политики модернизации образовательной системы Грузии включает в себя повышение средней заработной платы учителей, администрации школ, директоров, а также преподавателей в вузах. По словам министра образования, науки, культуры и спорта республики М. Батиашвили, к 2022 г. будут достигнуты заработные платы в размере 1500 лари (около 500 долларов США) и 2000 лари (около 650 долларов США) для школьного педагога и учителя высшей категории соответственно.

4. Внедрение ваучерной системы.

Термину «ваучер» в «Законе об общем образовании» дано следующее определение: «Ваучер - переданный государством учащемуся подлежащий обращению финансовый инструмент, который может быть выпущен как в материализованной, так и в нематериализованной форме и предназначен для финансирования получения учащимся общего образования». Что касается региона Квемо-Картли, то введение ваучерной системы не принесет ожидаемого положительного эффекта: объединение школ приведет к сокращению числа общеобразовательных учреждений в провинции (при расчете, что на одного ученика будет выделено 30 долларов США). Итог несложно просчитать - вырастет безработица, начнется кризис, экономическая нестабильность, а местное население останется без возможности получения среднего общего, а затем и высшего образования.

Анализ вопроса получения высшего образования представителями национальных меньшинств в Грузии и мер по усовершенствованию образовательной политики показывает, что «корень» проблем социальной жизни азербайджанцев Грузии кроется именно в правительственном подходе к меньшинствам, которые оказываются интегрированными в экономическую жизнь страны больше, чем в социальную, политическую, духовную ее сферы. Очевидно, что отсутствие не только калькированной с евростандартов, но продуманной, адаптированной к местным условиям системы мер поддержки образования национальных меньшинств, отвечающей реалиям этнолингвистического и экономического развития краев и муниципалитетов Грузии, приводит к диспропорциям и социальной напряженности.

\section{Заключение}

Таким образом, проходящая вполне типовой для постсоветских республик комплекс амбициозных реформ Болонского формата, грузинская система высшего образования и науки, при ее соответствующем качественном совершенствовании и улучшении материально-технической базы, стремится в перспективе соответствовать европейскому уровню. Только будущее протестирует «на прочность» все прилагаемые модернизационные усилия и сам вектор перемен.

\section{Список литературы}

1. Амирджанова Ш. Азербайджанцы в Грузии: почему им так сложно получить хорошее образование и перспективную работу. JAM News. 2019. URL: https://jam-news.net/ (дата обращения: 25 сентября 2019).

2. Борисова Е.Р. 2006. Положения Болонской декларации в системе образования. Чебоксары, Новое время, 311.

3. Васадзе Н.Ш. 1975. Из истории высшего педагогического образования в Грузии. Тбилиси, Издательство Тбилисского университета, 66.

4. Вачнадзе Г.Н. 2009. Деловая Грузия. М., ООО «Полпред Справочники», 209.

5. Вачнадзе Г.Н. и др., 1993. История Грузии (с древнейших времен до наших дней). Тбилиси, Артануджи, 474.

6. Гаджиев К.С. 2001. Геополитика Кавказа. М., Международные отношения, 462.

7. Гретченко А.И. 2005. Болонский процесс: плюсы, минусы, за и против... М., Наука, 100.

8. Грузия в цифрах: итоги последней переписи населения. Грузинский язык за 3 месяца.

2014. URL: https://gruzinskij.ru/o-gruzii/facts/gruziya-v-cifrax.html (дата обращения: 30 апреля 2020).

9. Закон Грузии об общем образовании. 2010. Статья 2. Разъяснение терминов. Тбилиси, 2005. 
10. Капальбо К. 2019. Грузия: Люди. Горы. Виноград. М., КоЛибри, Азбука-Аттикус, 428.

11. Кожокин Е. М. 2001. Грузия: проблемы и перспективы развития. Т. 1. Рос. ин-т стратегич. исслед. М., РИСИ, 321.

12. Месхиа Ш.А. 1968. История Грузии (краткий обзор). Тбилиси, ТбГУ, 47.

13. Новрузов Д.А. 1991. Традиционная и современная материальная культура азербайджанцев, проживающих в Грузии. Автореф. дис. на соискание ученой степени кандидата исторических наук. Баку, 21.

14. Рцхиладзе Г.В. 2018. Фактор внешнего авторитета для «малых» государств и интеграция на постсоветском пространстве. Вестник Российского университета дружбы народов. Серия: Международные отношения, 18 (1): 33-48.

15. «Тэласи» оформило соглашение с Техническим университетом и Академией энергетики Грузии. REGNUM. 2006. URL: https://regnum.ru/news/economy/644935.html (дата обращения: 20 ноября 2019). Тропос, 256.

16. Цибахашвили Г.И. 2001. Самоучитель грузинского языка. М. - Элиста-Гродно;

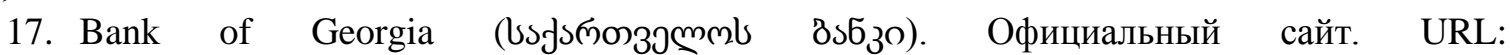
https://bankofgeorgia.ge/en/retail/main (дата обращения: 30 сентября 2019).

18. European Commission. Projects in Georgia - European External Action Service. Официальный сайт.

URL: https://ec.europa.eu/search/?QueryText=georgia\&op=Search\&swlang=en\&form_build_id=form-

BLXVUcNX8q6o4DSZPXINwHpmc9KFaqXHcJXqB53DMac\&form_id=nexteuropa_europa_search_se arch_form (дата обращения: 5 мая 2020 года). XXI, 205.

19. Gachechiladze R. 2004. The New Georgia: Space, Society, Politics. London, Routledge,

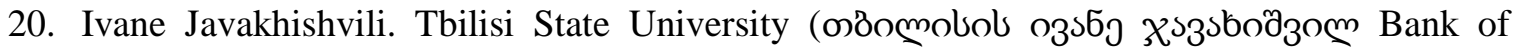

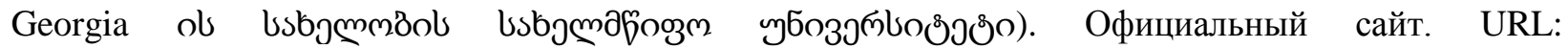
https://www.tsu.ge/en/ (дата обращения: 30 сентября 2019).

21. Ministry of Education, Science, Culture and Sport of Georgia (bsfs(nom3jmmls

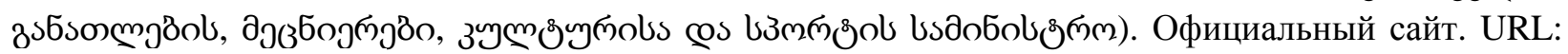
https://www.mes.gov.ge/ (дата обращения: 30 сентября 2019).

22. Ömərli V. 2001. Qarayazi. I hissə. Baki - Çaşığlu, 760.

\section{References}

1. Amirdzhanova Sh. Azerbajdzhancy v Gruzii: pochemu im tak slozhno poluchit' horoshee obrazovanie i perspektivnuju rabotu [Azerbaijanis in Georgia: why it is so difficult for them to get a good education and promising work]. JAMS News. 2019. Available at: https://jam-news.net/ (data obrashhenija: 25 Sentyabrya 2019) (in Russian).

2. Borisova E.R. 2006. Polozhenija Bolonskoj deklaracii v sisteme obrazovanija [The Provisions of the Bologna Declaration in the Education System]. Cheboksary, Publ. New time, 311 p.

3. Vasadze N.Sh. 1975. Iz istorii vysshego pedagogicheskogo obrazovanija v Gruzii [From the History of Higher Teacher Education in Georgia]. Tbilisi, Publ. TSU, 66 p.

4. Vachnadze G.N. 2009. Delovaja Gruzija [Business Georgia]. Moscow, Publ. LLS «Polpred Reference books», $209 \mathrm{p}$.

5. Vachnadze i dr., 1993. Istorija Gruzii (s drevnejshih vremen do nashih dnej) [History of Georgia (From Ancient Times to the Present Day)]. Tbilisi, Publ. Artanudzhi, 47 p.

6. Gadzhiev K.S. 2001. Geopolitika Kavkaza [Geopolitics of the Caucasus]. Moscow, Publ. International relationships, $462 \mathrm{p}$.

7. Gretchenko A.I. 2005. Bolonskij process: pljusy, minusy, za i protiv... [Bologna process: pros, cons, pros and cons ...]. Moscow, Publ. The sience, 100 p.

8. Gruzija v cifrah: itogi poslednej perepisi naselenija. Gruzinskij jazyk za 3 mesjaca [Georgia in figures: results of the last population census. Georgian language in 3 months]. 2014. Available at: https://gruzinskij.ru/o-gruzii/facts/gruziya-v-cifrax.html (data obrashhenija: 30 aprelja 2020).

9. Zakon Gruzii ob obshhem obrazovanii. 2010. Stat'ja 2. Razjasnenie terminov [Law of Georgia on General Education. 2010. Article 2. Clarification of Terms]. Tbilisi, 2005. 
10. Kapal'bo K. 2019. Gruzija: Ljudi. Gory. Vinograd [Tasting Georgia: A Food and Vine Journey in the Caucasus]. Moscow, Publ. KoLibri, Azbuka-Attikus, 428 p.

11. Kozhokin E.M. 2001. Gruzija: problemy i perspektivy razvitija [Georgia: Problems and Development Prospects. T. 1. Ros. in-t strategich. Issled]. Moscow, Publ. RISI, 321 p.

12. Meshia Sh.A. 1968. Istorija Gruzii (kratkij obzor) [History of Georgia (short review)]. Tbilisi, Publ. TSU, $47 \mathrm{p}$.

13. Novruzov D.A. 1991. Tradicionnaja i sovremennaja material'naja kul'tura azerbajdzhancev, prozhivajushhih v Gruzii [Traditional and Modern Material Culture of Azerbaijanis Living in Georgia]. Avtoref. dis. na soiskanie uchenoj stepeni kandidata istoricheskih nauk. Baku, $21 \mathrm{p}$.

14. Rchiladze G.V. 2018. Faktor vneshnego avtoriteta dlja «malyh» gosudarstv i integracija na postsovetskom prostranstve [Factor of External Authority for Small States and Integration in the PostSoviet Space]. Vestnik RUDN. International relations [Bulletin of the Peoples' Friendship University of Russia. Series: International Relations], 18 (1): 33-48. DOI: 10.22363/2313-0660-2018-18-1-33-48.

15. «Tjelasi» oformilo soglashenie s Tehnicheskim universitetom i Akademiej jenergetiki Gruzii [«Telasi» signed an agreement with the Technical University and the Academy of Energy of Georgia]. Available at: https://regnum.ru/news/economy/644935.html (accessed 20 November 2019).

16. Cibahashvili G.I. 2001. Samouchitel' gruzinskogo jazyka [Georgian Language Tutorial]. Moscow-Elista city, Publ. Tropos, 256 p.

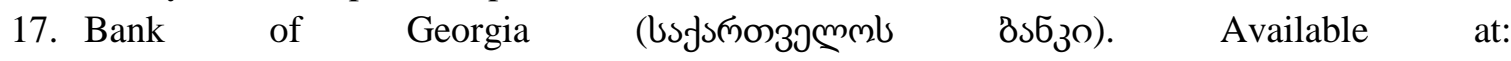
https://bankofgeorgia.ge/en/retail/main (accessed 30 September 2019).

18. European Commission. Projects in Georgia - European External Action Service. Available at: https://ec.europa.eu/search/?QueryText=georgia\&op=Search\&swlang=en\&form_build_id=formBLXVUcNX8q6o4DSZPXINwHpmc9KFaqXHcJXqB53DMac\&form_id=nexteuropa_europa_search_se arch_form (accessed 5 May 2020).

19. Gachechiladze Revaz, 2004. The New Georgia: Space, Society, Politics. London, Raitledge, XXI, $205 \mathrm{p}$.

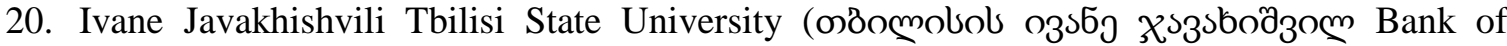

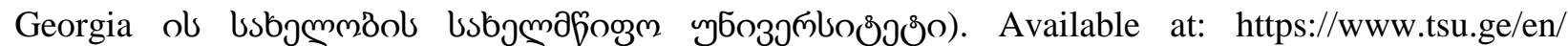
(accessed 30 September 2019).

21. Ministry of Education, Science, Culture and Sport of Georgia (bsfsnon $39 \mathrm{~mm} b$

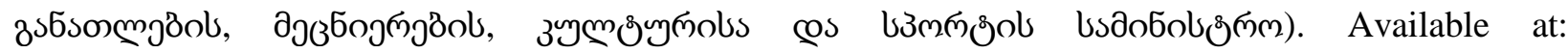
https://www.mes.gov.ge/ (accessed 30 September 2019).

22. Omarli V. 2001. Qarayazi. Part I. Baku. Publ. Chashioglu, 760 p.

\section{ИНФОРМАЦИЯ ОБ АВТОРЕ}

Черешнева Лариса Александровна, доктор исторических наук, профессор института истории, права и общественных наук Липецкого государственного педагогического университета имени П.П. Семенова-ТянШанского, г. Липецк, Россия

Гаджиева Улкар, студент кафедры управления института истории, права и общественных наук Липецкого государственного педагогического университета имени П.П. Семенова-ТянШанского, г. Липецк, Россия

\section{INFORMATION ABOUT THE AUTHOR}

Larisa A. Chereshneva, Doctor of Historical Sciences, Professor of the Institute of History Law and Social Sciences of the Lipetsk State Pedagogical University named after P.P. SemenovTyan-Shanskiy, Lipetsk, Russia

Ulkar Gadjieva, student of the department of the management of the Institute of History Law and Social Sciences of the Lipetsk State Pedagogical University named after P.P. Semenov-TyanShanskiy, Lipetsk, Russia 